\title{
Frontal brain dysfunction in alcoholism with and without antisocial personality disorder
}

This article was published in the following Dove Press journal:

Neuropsychiatric Disease and Treatment

22 May 2009

Number of times this article has been viewed

\author{
Marlene Oscar-Berman ${ }^{1,2}$ \\ Mary MValmas ${ }^{1,2}$ \\ Kayle S Sawyer ${ }^{1,2}$ \\ Shalene M Kirkley' \\ David A Gansler ${ }^{3}$ \\ Diane Merritt ${ }^{1,2}$ \\ Ashley Couture'
}

'Department of Veterans Affairs Healthcare System, Boston Campus, Boston, MA, USA; ${ }^{2}$ Boston University School of Medicine, Boston, MA, USA ${ }^{3}$ Suffolk University, Boston, MA, USA

Correspondence: Marlene Oscar-Berman Boston University School of Medicine, L-8I5, 72 East Concord Street, Boston, MA 02118, USA

Tel +16176384803

Fax +I 6176384806

Email oscar@bu.edu

\begin{abstract}
Alcoholism and antisocial personality disorder (ASPD) often are comorbid conditions. Alcoholics, as well as nonalcoholic individuals with ASPD, exhibit behaviors associated with prefrontal brain dysfunction such as increased impulsivity and emotional dysregulation. These behaviors can influence drinking motives and patterns of consumption. Because few studies have investigated the combined association between ASPD and alcoholism on neuropsychological functioning, this study examined the influence of ASPD symptoms and alcoholism on tests sensitive to frontal brain deficits. The participants were 345 men and women. Of them, 144 were abstinent alcoholics (66 with ASPD symptoms), and 201 were nonalcoholic control participants (24 with ASPD symptoms). Performances among the groups were examined with Trails A and B tests, the Wisconsin Card Sorting Test, the Controlled Oral Word Association Test, the Ruff Figural Fluency Test, and Performance subtests of the Wechsler Adult Intelligence Scale. Measures of affect also were obtained. Multiple regression analyses showed that alcoholism, specific drinking variables (amount and duration of heavy drinking), and ASPD were significant predictors of frontal system and affective abnormalities. These effects were different for men and women. The findings suggested that the combination of alcoholism and ASPD leads to greater deficits than the sum of each.
\end{abstract}

Keywords: alcoholism, antisocial personality disorder (ASPD), frontal brain system, neuropsychological deficits, reward system

\section{Introduction}

Antisocial personality disorder (ASPD) and alcoholism are often comorbid conditions. Epidemiological and clinical studies consistently have found a strong association between alcoholism and a lifetime history of antisocial personality traits and symptoms among recovering alcoholics. ${ }^{1-3}$ Motives for drinking, ${ }^{4}$ as well as behaviors such as heavy drinking and alcohol dependence, may be associated with ASPD symptomatology. Moreover, early-onset alcoholics have a severe clinical presentation that may be related to a history of conduct disorder and progression to ASPD, ${ }^{5,6}$ and strong associations between ASPD and alcoholism are related to poor treatment outcomes and increased clinical severity. ${ }^{3}$

Several studies have reported that novelty seeking, ${ }^{5}$ impulsivity, ${ }^{7}$ affective instability, ${ }^{4}$ disinhibition, ${ }^{8}$ and negative affectivity ${ }^{9}$ are related to chronic alcohol use and dependence. Similarly, individuals with ASPD often display a reduced attentional capacity ${ }^{10}$ and abnormal perseverative responding. ${ }^{10-12}$ These various characteristics associated with alcoholism ${ }^{13,14}$ and $\mathrm{ASPD}^{15,16}$ likely reflect abnormalities in the functioning of frontal brain systems, ${ }^{11,17,18}$ although it is not clear whether the presence 
of ASPD symptoms is a risk marker or a reflection of chronic alcoholism.

There is further evidence of possible premorbid frontal abnormalities in individuals at risk for alcoholism, a subset of whom display impulsivity, rule breaking, insensitivity to reinforcement, poor response to social censure and physical punishment, and ASPD. ${ }^{19-22}$ Type II alcoholic personalities (early drinking onset, antisocial personality characteristics, and resistance to treatment $)^{23}$ may be the most vulnerable to frontal system deficits, as well as to emotional processing difficulties. ${ }^{24,25}$ Functional and structural neuroimaging techniques have revealed frontal brain abnormalities in alcoholics and in individuals with ASPD. ${ }^{13,18,26-28}$ However, little is known about the characteristics of frontal dysfunction in alcoholics with ASPD symptoms. Therefore, in the present study, in examining the association between alcoholism and ASPD symptoms on neuropsychological tests sensitive to different aspects of frontal system function, we hypothesized that the interaction would reveal greater deficits than the sum of both conditions.

The frontal lobes are connected with all of the other lobes of the brain, and they receive and send fibers to many subcortical structures as well. ${ }^{29}$ The posterior region of the frontal lobes controls motor functions, and the anterior region of the frontal lobes (prefrontal cortex) plays a regulatory role within the brain. Prefrontal cortex is host to at least two subsystems: dorsolateral and orbitofrontal (on the ventral surface). ${ }^{29,30}$ Whereas the dorsolateral system contains extensive reciprocal connections with other neocortical sites, its connections with limbic sites are less striking than are those of the orbitofrontal system. The dorsolateral system is important for successful performance on tasks that require intact visuospatial, mnemonic, attentional, and executive functions, for cognitive set shifting and rule discovery, and for verbal and spatial working memory (see Fuster, ${ }^{29}$ Miller and Cummings, ${ }^{31}$ and Royall and colleagues ${ }^{32}$ for reviews). By contrast, functions involved in response inhibition and emotional responsiveness have been linked to the ventral surface or orbitofrontal system, which is extensively connected with basal forebrain and limbic structures. The orbitofrontal system is especially important for maintaining normal inhibitory influences on behavior, such as inhibiting abnormal perseverative responding, ${ }^{30}$ including disengagement from previously reinforced responses, ${ }^{33}$ and control over untoward social behaviors. Research on prefrontal functioning in alcoholics ${ }^{34}$ and individuals with ASPD symptoms ${ }^{11}$ has suggested that both groups may be more impaired on tasks sensitive to compromised orbitofrontal functioning, as compared to tasks sensitive to dorsolateral prefrontal dysfunction. One purpose of the present study was to employ tests that can evaluate the integrity of both the dorsolateral and orbitofrontal brain systems, in order to determine whether alcoholics with and without ASPD symptoms differ with respect to performance on those tests.

A secondary purpose of the present study was to assess gender differences in disturbances of prefrontal functioning. Characteristics of antisocial behavior that play a role in abnormal aggressive behaviors, affective instability, disinhibition, impulsivity, and impaired problem solving, ${ }^{35-40}$ are more pronounced in men than in women. Moreover, recent meta-analytic reviews of frontal system function in ASPD reported that antisocial groups performed worse than nonASPD groups, ${ }^{16}$ and the most robust findings were observed for men. This suggests that there may be key ways in which men and women differ with respect to personality traits, ${ }^{41}$ which in turn, may be associated with specific neurological underpinnings. In fact, although many research studies have explored the relationship between antisocial traits and disturbances in frontal brain systems, ${ }^{24,42}$ and research on gender differences in alcoholism suggest that women may be more vulnerable than men to its pathological consequences, ${ }^{43,44}$ few studies have directly compared alcoholic men and women with respect to ASPD symptoms. ${ }^{20,45}$ Likewise, few studies have examined frontal system functioning among male and female participants with comorbid antisocial symptoms and alcohol use disorders. ${ }^{24,46}$ We reasoned that if the effect size associated with gender is equivalent for alcoholism and for ASPD, then alcoholic men and women with ASPD symptoms would be similarly impaired. However, if women and men are differently influenced by alcoholism and by ASPD, we expected a more complicated picture to emerge.

\section{Methods}

\section{Participants}

A total of 345 participants (172 males) took part in the study. All of the participants were right-handed English-speaking men and women from the Boston area, with comparable socioeconomic backgrounds. The groups consisted of 144 abstinent alcoholics (66 with ASPD symptoms), and 201 healthy nonalcoholic control participants (24 with ASPD symptoms). See Table 1 for characteristics of the research participants.

Participation by alcoholic and control participants alike was solicited by the same methods. Many potential participants responded to flyers posted in the Neurology, Psychology, Psychiatry, Medical, and Outpatient Services at 


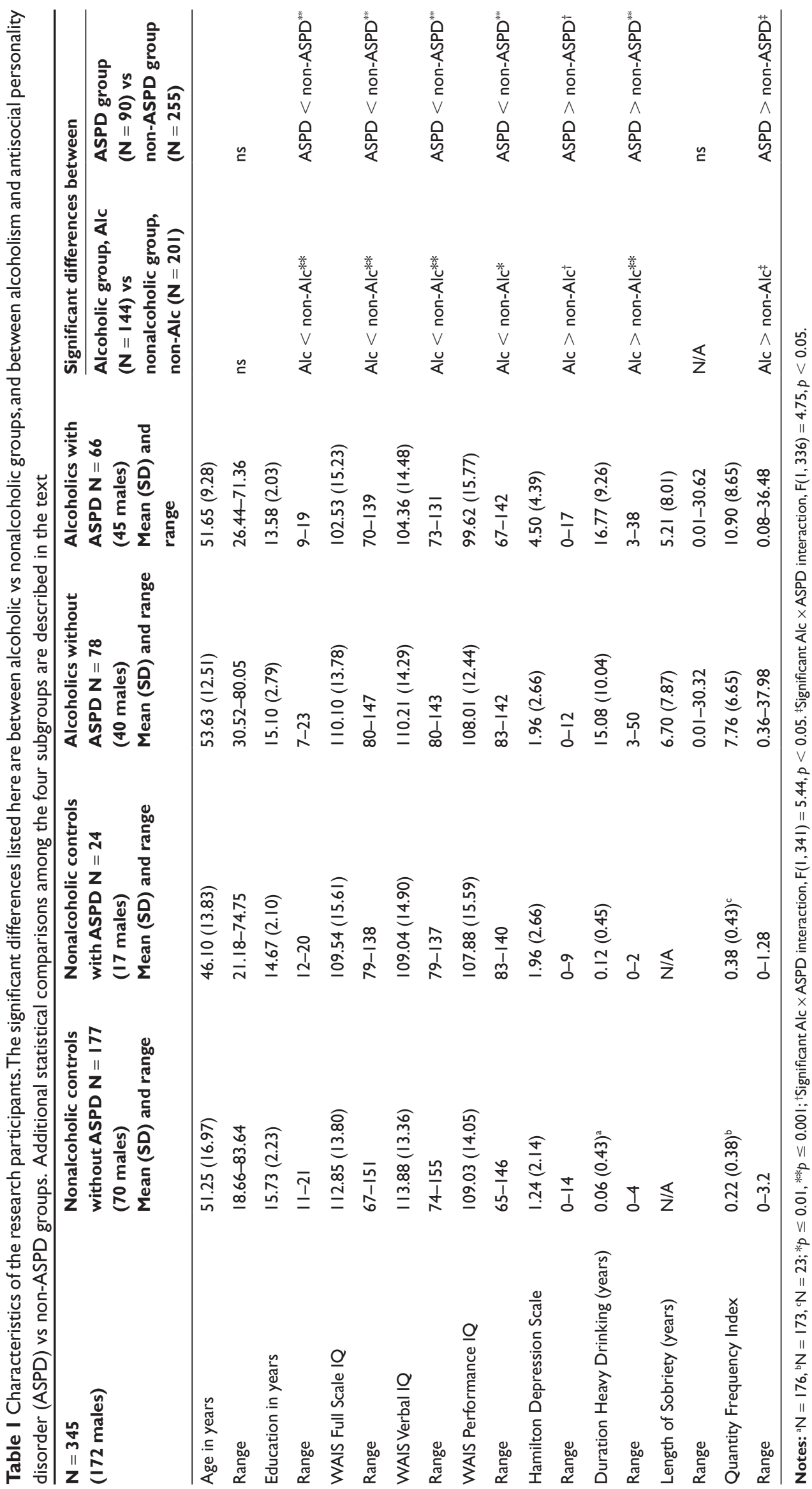


the Boston Campus of the Department of Veterans Affairs (VA) Healthcare System, Boston University Medical Center, and VA after-care programs in the Boston area. Other individuals responded to newspaper and Internet advertisements. Informed consent for participation in the research was obtained from each subject prior to testing, and participants were reimbursed for time and travel expenses.

\section{Assessments}

Potential participants were given a medical history interview and a modified Computerized Diagnostic Interview Schedule (DIS Version III-Revised ${ }^{47}$ or Version IV $^{48}$ ) which provides psychiatric diagnoses according to criteria established by the American Psychiatric Association (DSM-III-R ${ }^{49}$ or DSM$\left.I^{50}\right)$. Participants were excluded from further investigation if they endorsed any of the following criteria based on their initial interview, referral sources, medical history, or DIS scores: English was not their first (or one of their first) language(s); history of dyslexia; uncorrected abnormal vision or hearing problem; history of neurological dysfunction (eg, due to alcohol-induced persisting amnestic disorder, major head injury, loss of consciousness for more than 15 minutes, stroke, epilepsy or seizures unrelated to alcohol use or withdrawal); current use of psychoactive medication; history of electroconvulsive shock therapy; and/or history of significant drug use (other than alcohol). Participants were also excluded if they met diagnostic criteria for significant psychiatric disorder such as bipolar disorder, mania, hypomania, and schizophrenia-spectrum disorders.

All of the participants were given a structured interview in which they were questioned about their drinking patterns. A Quantity Frequency Index (QFI), which takes into consideration the amount, type, and frequency of use of alcoholic beverages, either over the last six months (for the nonalcoholics), or over the six months preceding cessation of drinking (for the alcoholics), was calculated for each participant. ${ }^{51}$ For the alcoholics, information also was obtained about length of abstinence and the number of years of heavy drinking (duration of heavy drinking [DHD]; quantified as greater than 21 drinks per week). Alcoholic participants met DSM ${ }^{49,50}$ criteria for alcohol abuse or dependence for at least five years. All but seven alcoholics had abstained from alcohol use for at least four weeks prior to testing; three were women (two with ASPD symptoms), and four were men (one with ASPD symptoms). Alcoholics with and without ASPD symptoms did not differ with respect to length of sobriety $(t=1.13, p=0.26)$. We excluded control participants who reported periods of prolonged heavy drinking, as determined by the results of our screening interviews; the mean DHD for all nonalcoholics was 0.07 years (range $0-4$ years).

Psychometric properties of the assessment instruments are available in the referenced citations for each of the standardized tests that we used. Norms have been established among alcoholics for the Wechsler Adult Intelligence Scale (WAIS), Wechsler Memory Scale (WMS), Wisconsin Card Sorting Test (WCST), and Trails, ${ }^{52}$ but to our knowledge, none of the measures we used have norms relevant to ASPD populations. The DIS has been tested for reliability and validity in diagnosing ASPD among substance abusers, including alcoholics. ${ }^{53,54}$ Psychometric properties are not available for our medical and alcohol screening interviews.

In our study, we assessed antisocial personality symptoms with the DIS. ${ }^{47,48}$ According to the DSM criteria, a diagnosis of ASPD requires antisocial behavior symptoms since age 15 , and evidence of conduct disorder with onset before age 15 . However, we examined participants who met DSM criteria for ASPD symptoms rather than ASPD diagnosis, because for a large portion of the participants, we had no information regarding a history of conduct disorder before age 15 . Thus, we considered syndromal antisocial behavior since age 15 . This is an important distinction, because several studies have reported that the presence of conduct disorder among alcoholics with ASPD is associated with more severe alcohol abuse, poorer treatment outcomes, and poorer performance on neuropsychological tests. ${ }^{3,55}$ Moreover, among young adults with early onset alcoholism, those with a history of conduct disorder had poorer behavioral inhibition compared to those without conduct disorder. ${ }^{5}$

\section{Procedures}

In order to estimate general levels of intelligence and to obtain traditional measures of memory on the participants, we administered the WAIS ${ }^{56,57}$ and WMS. ${ }^{58,59}$ Three WAIS subtests (Digit Symbol, Block Design, and Picture Arrangement) were used as measures of frontal system function, including: attention, memory, social competency, motor speed, and visuospatial function. We also administered four additional neuropsychological tests that were particularly sensitive to frontal brain dysfunction: ${ }^{60,61}$ Trail Making Test; ${ }^{62}$ WCST; ${ }^{63}$ Controlled Oral Word Association Test (COWAT); ${ }^{64}$ and Ruff Figural Fluency Test (RFFT). ${ }^{65}$ Table 2 lists the tasks, as well as the various measures derived from each of them.

Trails $\mathrm{A}$ is a test of sequential-motor ability requiring individuals to connect an ordered series of numbered circles. Trails B adds a cognitive flexibility/mental-tracking component to the task by requiring the participant to alternate 
Table 2 Measures of frontal function

\begin{tabular}{|c|c|}
\hline Test & Measure \\
\hline Trail Making Test (Parts A and B) & - Age and education corrected T-Score \\
\hline Wisconsin Card Sorting Test (WCST) & $\begin{array}{l}\text { - Total number of correct responses } \\
\text { - Age and education corrected percentile ranking for perseverative responses } \\
\text { - Age and education corrected percentile ranking for conceptual level responses }\end{array}$ \\
\hline $\begin{array}{l}\text { Controlled Oral Word Association Test } \\
\text { (COWAT or FAS) }\end{array}$ & $\begin{array}{l}\text { - Total number of words } \\
\text { - Age and education corrected percentile ranking for total number of words } \\
\text { - Total number of perseverations }\end{array}$ \\
\hline Ruff Figural Fluency Test (RFFT) & - Total number of unique designs \\
\hline WAIS Digit Symbol subtest & $\begin{array}{l}\text { - Age and education corrected scaled score comprised of the coding score (number } \\
\text { of symbols correctly copied in } 120 \text { seconds) }\end{array}$ \\
\hline WAIS Block Design subtest & $\begin{array}{l}\text { - Age and education corrected scaled score comprised of the successful completion } \\
\text { of up to I4 designs within the time limit (time limits for each design range from } 30 \\
\text { seconds for the easiest designs to I } 20 \text { seconds for the most difficult designs) }\end{array}$ \\
\hline WAIS Picture Arrangement subtest & $\begin{array}{l}\text { - Age and education corrected scaled score comprised of the correct arrangement of } \\
\text { up to II pictures completed within the time limit (time limits for each design range } \\
\text { from } 30 \text { seconds for the easiest arrangements to } 120 \text { seconds for the most difficult } \\
\text { arrangements) }\end{array}$ \\
\hline
\end{tabular}

between number and letter series (1, A, 2, B, etc.). Both measures were transformed to $\mathrm{T}$-Scores using age and education norms. ${ }^{66}$ The WCST was administered to examine perseverative responding while set-switching, as well as to measure concept formation. This task was administered manually and scored by computer. Verbal and figural fluency were assessed with the COWAT and the RFFT, respectively. The COWAT (also called the FAS test) required participants to name as many words as they could that begin with the letter $\mathrm{F}$ (then $\mathrm{A}$, and then $\mathrm{S}$ ) within a 60 second period. For the RFFT, participants must draw as many unique designs as possible within 60 seconds by connecting dots in different patterns. The WAIS Performance subtests were administered in part because of their known sensitivity to visuospatial deficits in alcoholics, ${ }^{13,18}$ and also because they are sensitive to frontal functions such as attention, memory, and social competence. ${ }^{67}$ For the Coding portion of the Digit Symbol subtest, participants copied symbols that are paired with numbers, for 120 seconds. For the Incidental Learning and Free Recall portions, participants were asked to fill in the correct symbols that corresponded with the numbers and to draw as many symbols as they could accurately recall. The Block Design subtest requires participants to assemble nine threedimensional blocks such that they form patterns displayed on two-dimensional cards. The WAIS Picture Arrangement subtest requires participants to arrange pictures in an order that tells a coherent story involving interactions among people.

Of particular interest, because of their special putative sensitivity to frontal system dysfunction, were the following test measures: Trails A and B T-Scores; percentile ranking of the conceptual level responses and perseverative responses on the WCST; the percentile score and the total number of perseverative responses on the FAS test; the number of unique designs on the RFFT; and the Picture Arrangement subtest of the WAIS.

In addition, we administered the Hamilton Depression Scale $^{68}$ and the Profile of Mood States (POMS) ${ }^{69}$ to assess affect. The POMS contains well-documented measures of negative affect associated with alcohol use ${ }^{70,71}$ and antisocial symptoms, ${ }^{72}$ and we included it as an adjunct to our indices of frontal functioning.

Although none of the aforementioned tests can definitively assess deficits specific to damage of different subsystems within prefrontal brain circuitry, the following are considered more sensitive to dorsolateral prefrontal function than to orbitofrontal function: ${ }^{17,18}$ Trails T-Scores, WCST Conceptual Responses, FAS Percentile score, RFFT unique designs, and WAIS Digit Symbol and Block Design subtests. The tests considered to be more sensitive to orbitofrontal than to dorsolateral functions are WCST Perseverative Responses, FAS Perseverative Responses, WAIS Picture Arrangement, and measures of affect.

\section{Statistical analyses}

Relationships and interactions among variables were analyzed with SPSS Version $16 .{ }^{73}$ Hierarchical multiple regressions were conducted to predict performances on the neuropsychological test measures sensitive to frontal 
dysfunction, as well as the measures of affect. We selected the variables for inclusion in the analyses by first entering all of the variables of interest, as well as their interactions, into the hierarchical multiple regression models. We then removed the variables that were not significant predictors $(p=0.10)$, one at a time beginning with the interactions. Regression analyses included the following significant predictors: Alcohol group (AL), DHD, QFI, ASPD group, and Gender. Group membership (AL or ASPD) was defined according to the inclusion/exclusion criteria described earlier. Additionally, Age, Education, and Verbal IQ (VIQ) were examined as covariate predictors.

\section{Results}

The significant independent variables (ie, predictors) of interest in this study were AL, DHD, QFI, ASPD, and Gender. Table 3 shows the beta, standard error of beta, standardized beta, $t$ and $p$ values, as well as the bivariate, partial, and part correlations for each predictor in each significant model predicting the outcome measures. In addition, the $\mathrm{R}^{2}$-Change is listed to denote the additional variance contributed by the final predictor over and above the model with just the other predictors. In the models for the WAIS Digit Symbol Subtest, where there are multiple listings for $\mathrm{R}^{2}$-Change, the value for ASPD represents the $\mathrm{R}^{2}$-Change over and above each model with the alcohol variable alone (ie, AL, DHD, or QFI), and the value for Gender represents the $\mathrm{R}^{2}$-Change over and above each model with that same alcohol variable and ASPD.

When examining the influence of the possible confounding variables of age, education, and VIQ in relation to the measures of frontal and affective functioning, only those predictors that remained significant were retained. In addition, there were significant differences in the duration and amount of drinking among men and women. Therefore, we examined Gender in all our regression analyses, and only retained Gender as a predictor when it remained significant with DHD or QFI in the model. Examination for muliticollinearity of the noncategorical independent variables of DHD and QFI with Age, Education, and VIQ were significant but low: DHD with Age $(r=0.19)$ and with Education $(r=-0.30)$; QFI with Education $(r=-0.31)$ and with VIQ $(r=-0.24)$.

The deficits we observed did not appear to reflect generalized cognitive impairments in the alcoholics with ASPD symptoms. Specificity of their frontal-system deficits was indicated by the observations that (a) the various predictors were significant after we examined the influence of the possible confounding variables of Age, Education, and VIQ, and (b) the interaction of AL $\times$ ASPD was not statistically significant with respect to scores on the WAIS Vocabulary subtest, a measure of premorbid crystallized intelligence. ${ }^{56,74,75}$

\section{Measures of frontal function}

\section{Trails A and Trails B}

For the Trails A T-Score, the DHD $\times$ ASPD $\times$ Gender interaction was significant $\left(\mathrm{R}^{2}=0.04, \mathrm{~F}(7,333)=2.03\right.$, $p=0.05)$. For the Trails B T-Score, the three-way interaction of $\mathrm{AL} \times \mathrm{ASPD} \times$ Gender was significant $\left(\mathrm{R}^{2}=0.05\right.$, $\mathrm{F}(7,335)=2.30, p<0.05)$, as was DHD $\times$ ASPD $\times$ Gender $\left(\mathrm{R}^{2}=0.05, \mathrm{~F}(7,333)=2.73, p<0.01\right)$, and QFI $\times$ ASPD $\times$ Gender $\left(\mathrm{R}^{2}=0.04, \mathrm{~F}(7,330)=1.98, p=0.06\right)$. These results suggest that the combination of ASPD symptoms and drinking was associated with poor performance on the Trails A and $\mathrm{B}$ tasks, and that these relationships were more pronounced for women than for men.

\section{Wisconsin Card Sorting Task (WCST)}

For perseverative responses, the regression model with $\mathrm{AL}$ and ASPD as predictors was significant $\left(\mathrm{R}^{2}=0.04\right.$, $\mathrm{F}(2,339)=7.01, p=0.001)$, indicating that the alcoholic and the ASPD groups exhibited increased perseverative responding. For WCST conceptual responses, the regression model with the AL $\times$ ASPD interaction was significant $\left(\mathrm{R}^{2}=0.04, \mathrm{~F}(3,338)=4.91, p<0.01\right)$, indicating that the combination of alcoholism and ASPD symptoms was associated with worse conceptual scores than would be attributable to either condition alone. DHD and QFI did not significantly predict WCST perseverative or conceptual responses.

\section{Controlled Oral Word Association Test (COWAT or FAS)}

For the total number of words generated, two of the alcoholrelated measures (DHD and QFI) formed significant models with Gender (DHD: $\mathrm{R}^{2}=0.07, \mathrm{~F}(2,329)=12.61, p<0.001$; QFI: $\left.\mathrm{R}^{2}=0.07, \mathrm{~F}(2,329)=12.39, p<0.001\right)$. For age and education corrected FAS percentiles, two of the alcohol variables (AL and QFI) and ASPD formed significant models with Gender $\left(\mathrm{AL}: \mathrm{R}^{2}=0.05, \mathrm{~F}(2,334)=8.81, p<0.001\right.$; QFI: $\mathrm{R}^{2}=0.06, \mathrm{~F}(2,329)=9.75, p<0.001 ; \mathrm{ASPD}: \mathrm{R}^{2}=0.05$, $\mathrm{F}(2,334)=9.20, p<0.001)$. DHD and ASPD also predicted FAS percentiles $\left(\mathrm{R}^{2}=0.03, \mathrm{~F}(2,333)=5.20, p<0.01\right)$. The pattern presented was the same for all the drinking variables, that is, increased drinking was associated with fewer words produced. Women also generated more words than men. For FAS total number of perseverations, there was a significant three-way interaction of DHD $\times$ ASPD $\times$ Gender 


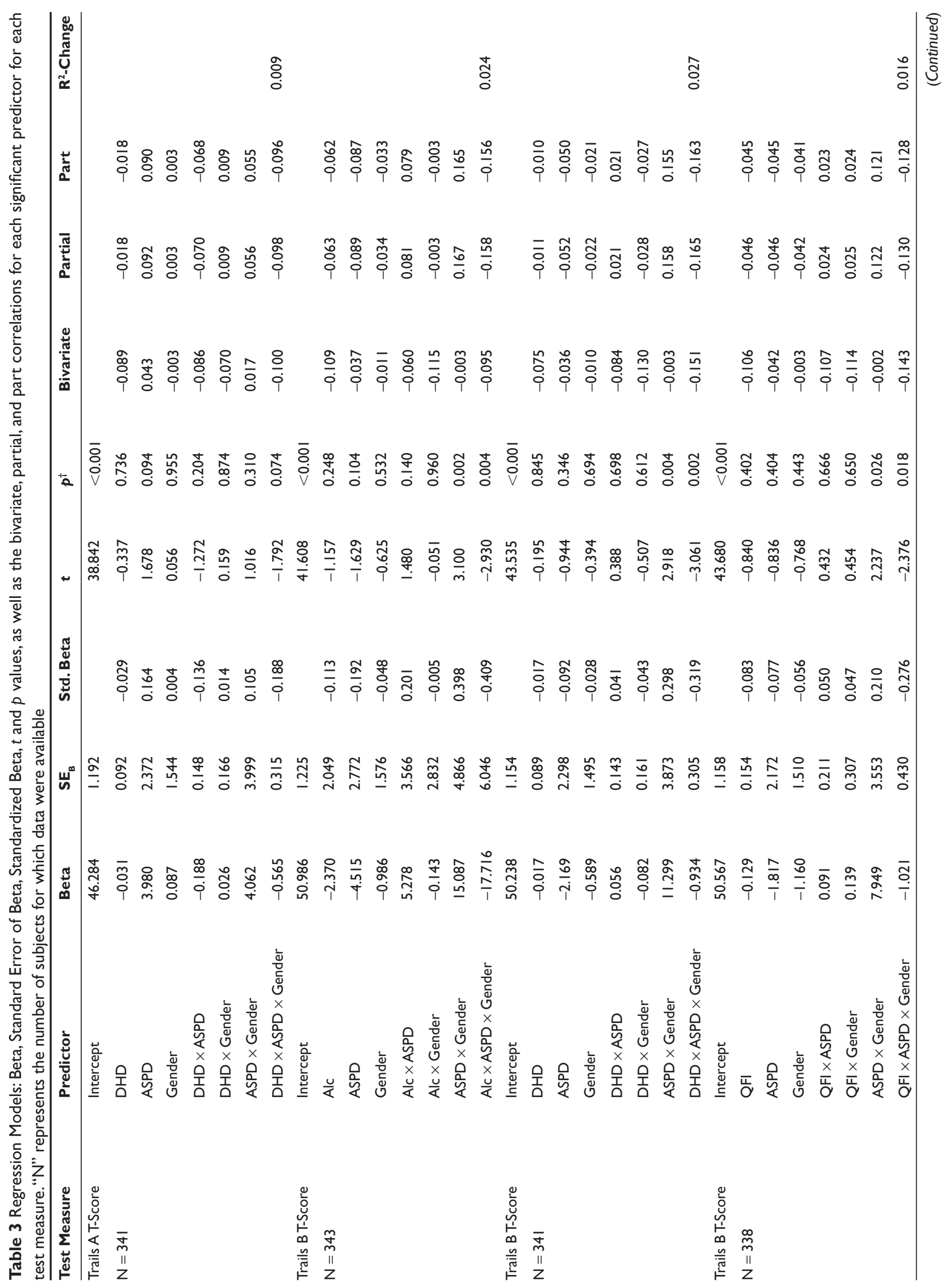




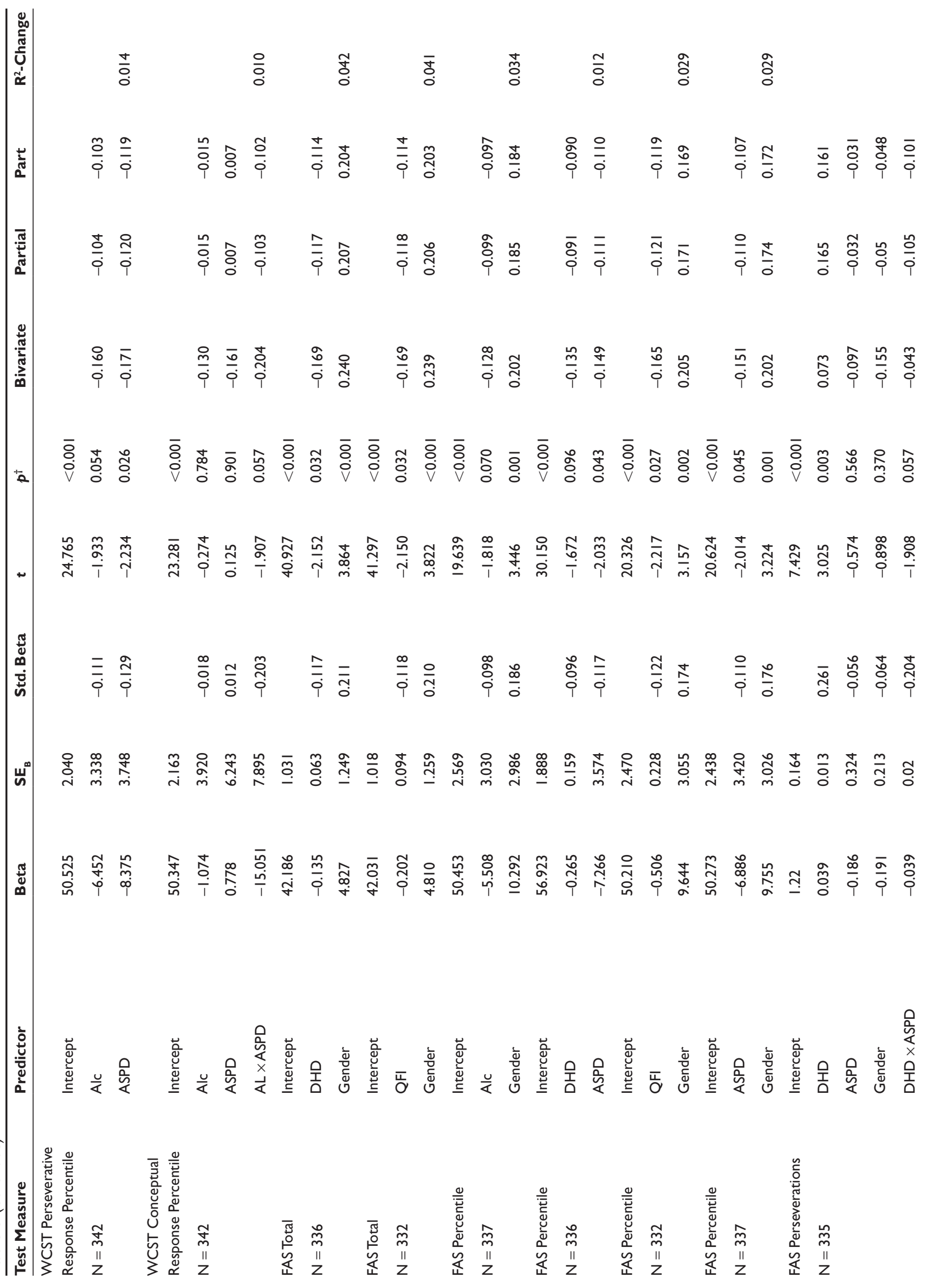




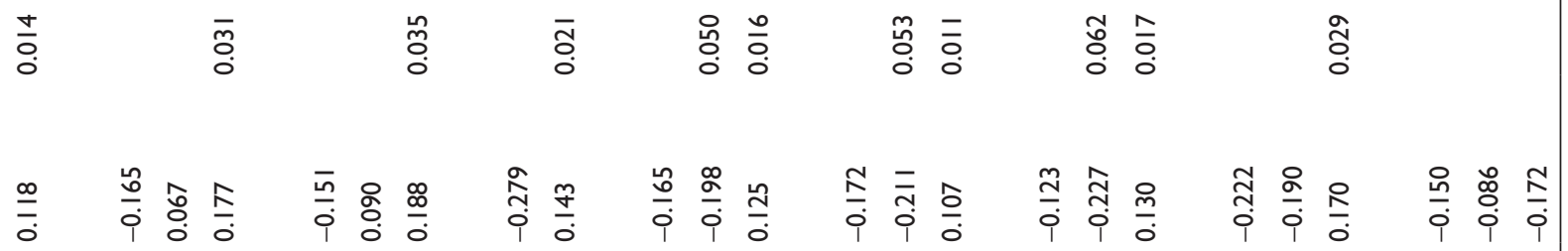

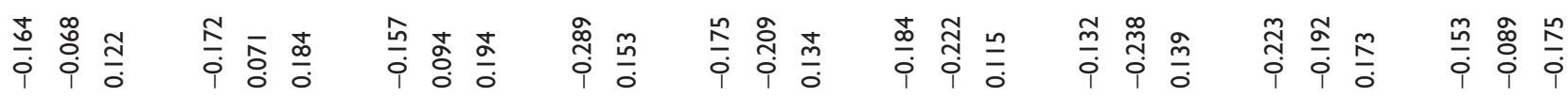

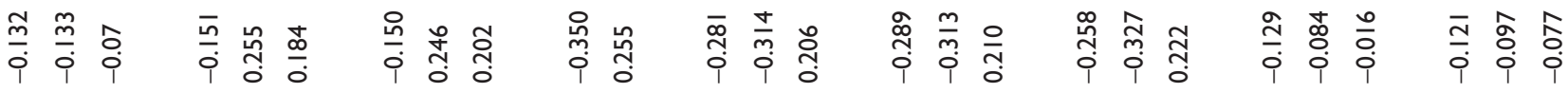

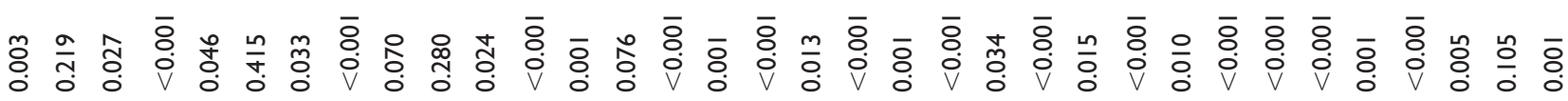

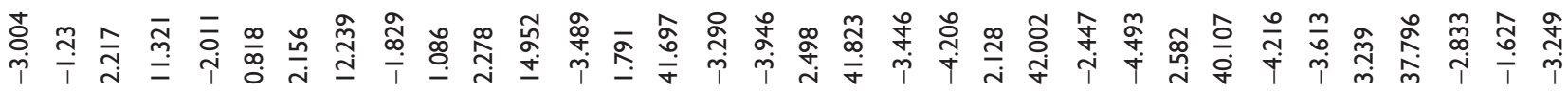

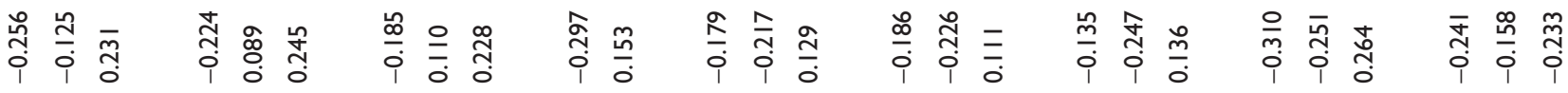

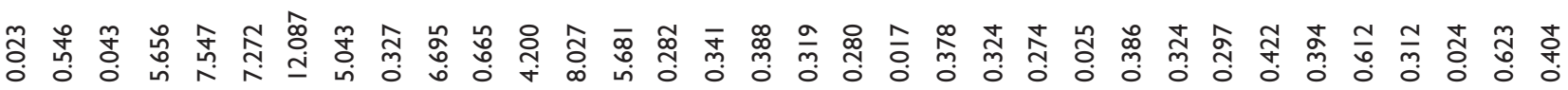

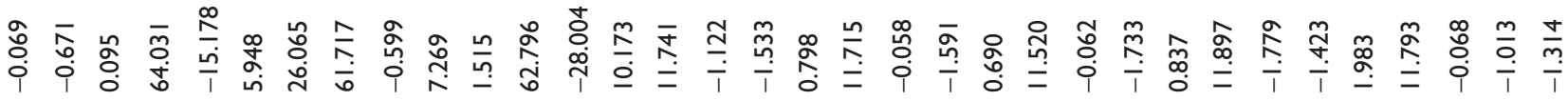

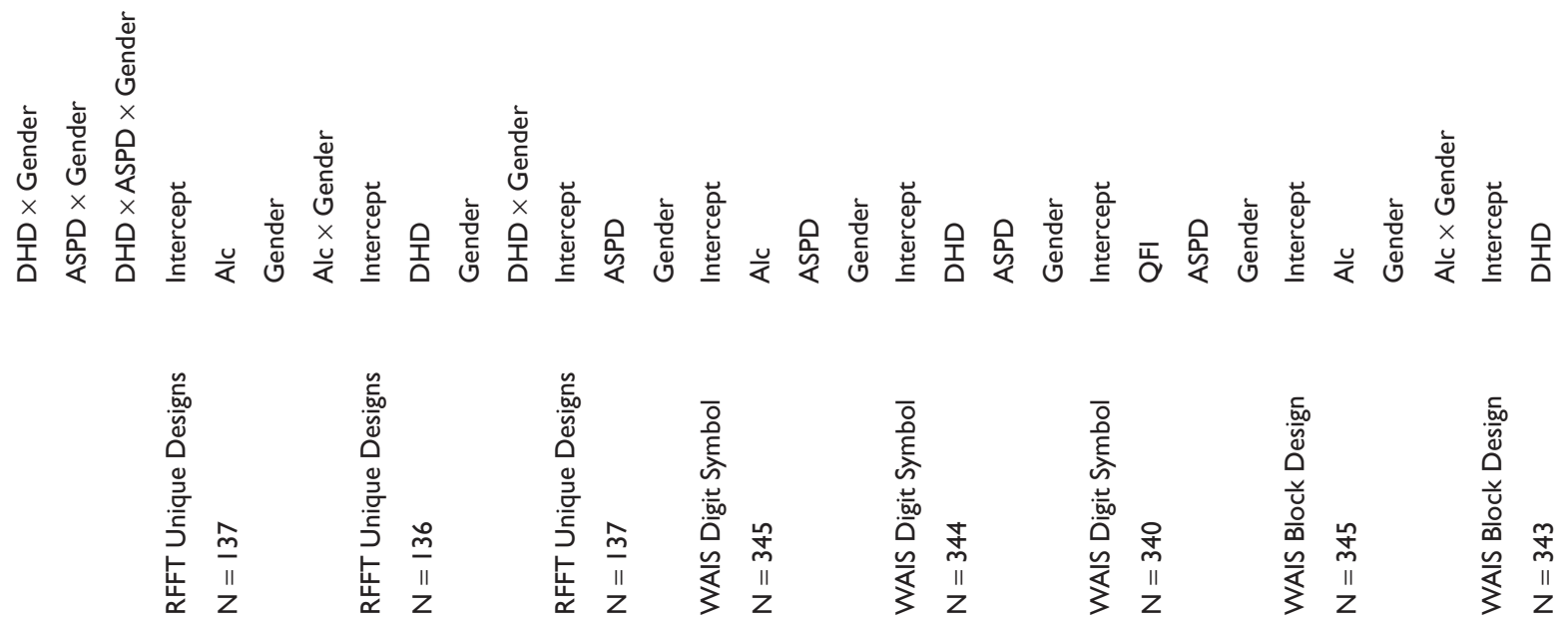




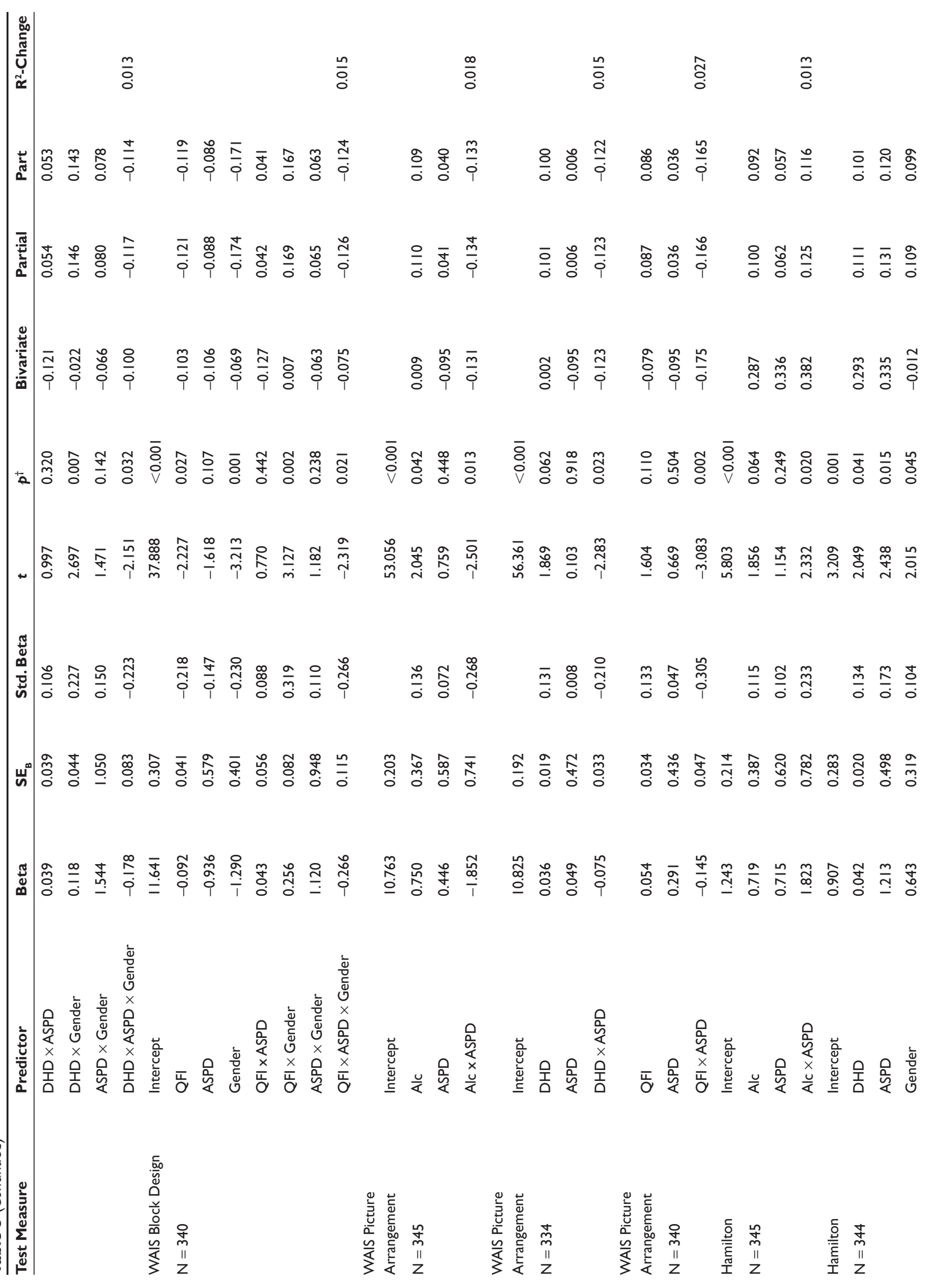




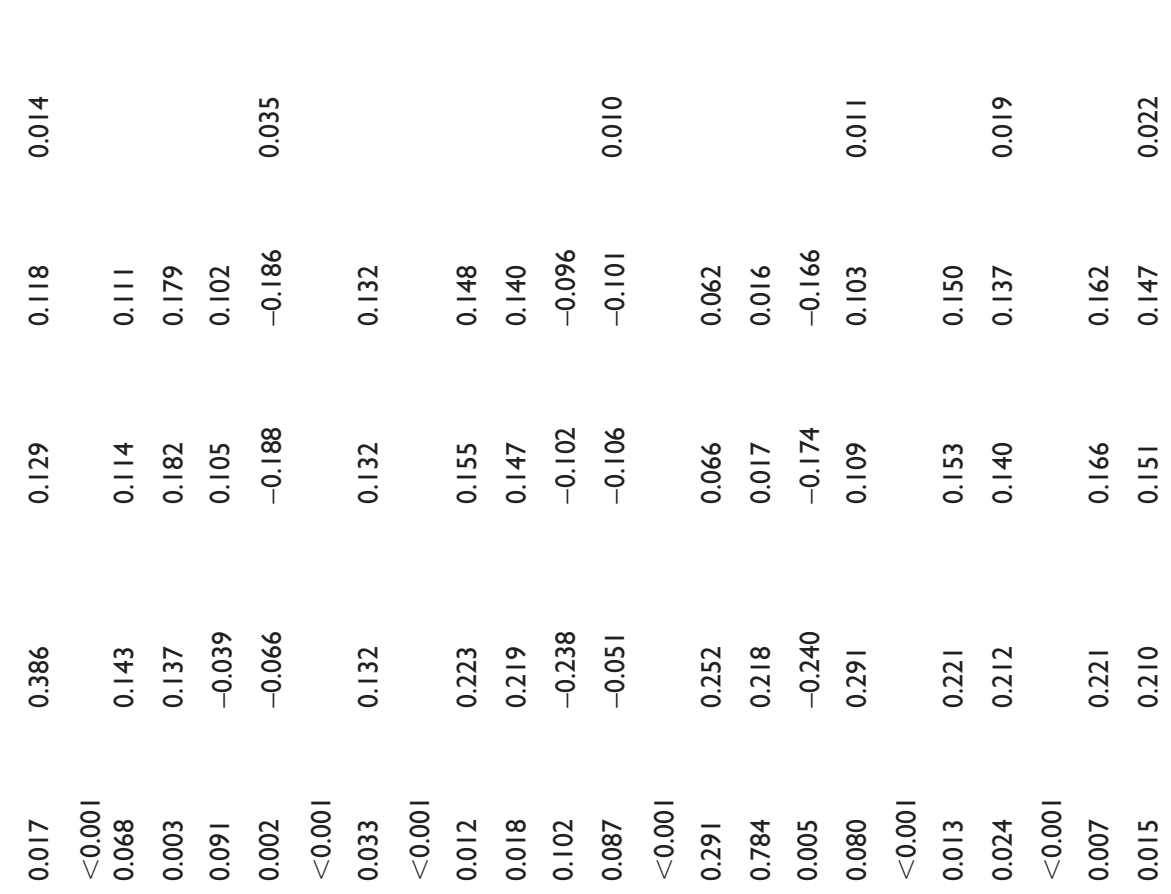

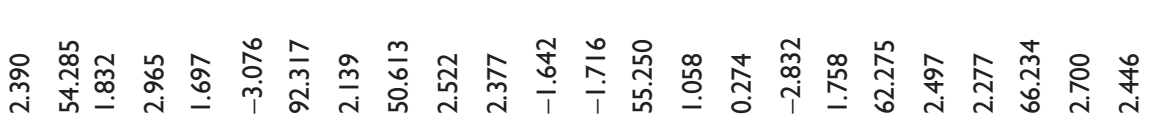

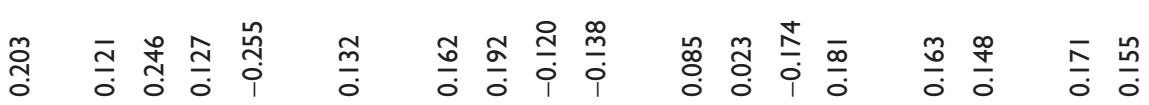

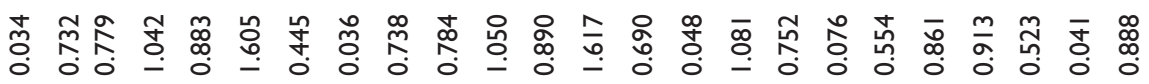

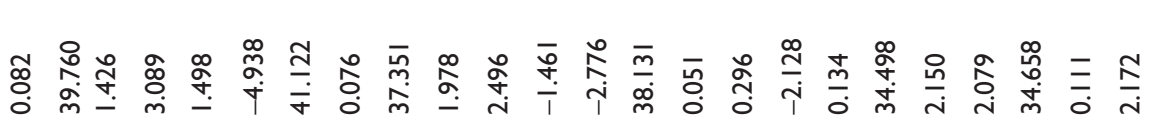

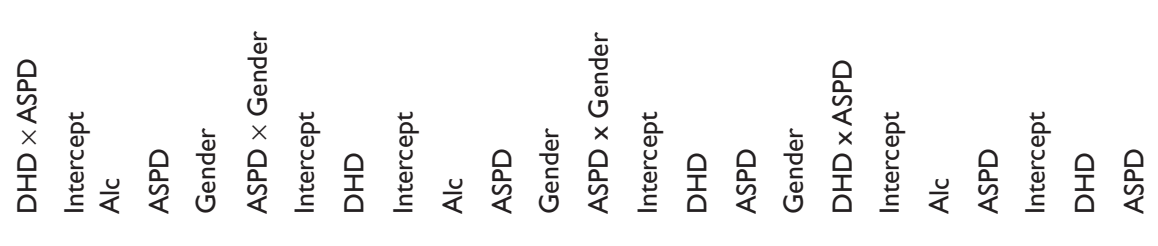

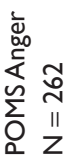

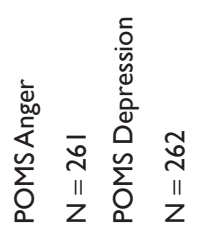

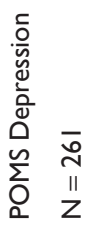

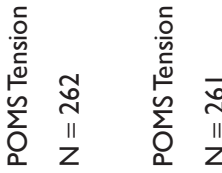

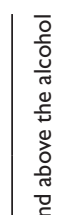

产

$\frac{1}{3}$

$\frac{\sqrt{2}}{\frac{2}{2}}$

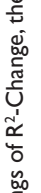

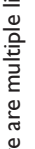

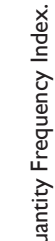

点高高离

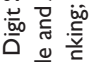

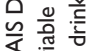

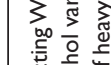

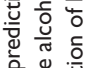

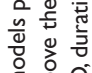

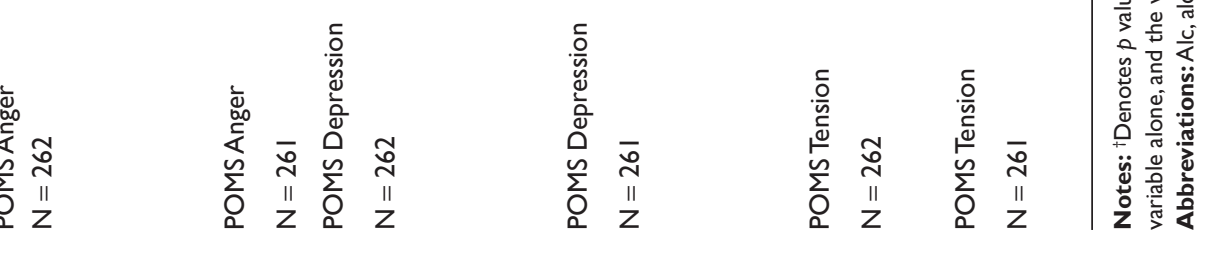


$\left(\mathrm{R}^{2}=0.08, \mathrm{~F}(7,327)=3.92, p<0.001\right)$. This suggests that for individuals without ASPD symptoms, men perseverated more in connection with DHD, whereas men with ASPD symptoms did not; this pattern was not observed for women.

\section{Ruff Figural Fluency Test (RFFT)}

Three multiple regression analyses for the RFFT number of unique designs revealed significant effects of AL, DHD, ASPD, and Gender. In the first regression model, the AL $\times$ Gender interaction significantly predicted the RFFT scores $\left(\mathrm{R}^{2}=0.10, \mathrm{~F}(3,133)=5.01, p<0.01\right)$. The second regression equation with the DHD $\times$ Gender interaction for the RFFT was significant $\left(\mathrm{R}^{2}=0.10, \mathrm{~F}(3,132)=4.92, p<0.01\right)$. Third, the model with ASPD and Gender was significant $\left(\mathrm{R}^{2}=0.14, \mathrm{~F}(2,134)=11.19, p<0.001\right)$. Together, these results indicated that alcoholic men made fewer unique designs than nonalcoholic men, but this relationship was not seen in women. In addition, longer DHDs were associated with fewer unique designs in men, but not in women. Participants with ASPD symptoms scored lower than those without, and the men scored lower than the women.

\section{WAIS subtests (age-scaled scores)}

For the WAIS Digit Symbol subtest, three multiple regression analyses were significant (for AL, DHD, and QFI), and in all three of them, ASPD and Gender also were significant predictors $\left(\mathrm{AL}: \mathrm{R}^{2}=0.15, \mathrm{~F}(3,341)=19.29, p<0.001\right.$; DHD: $\mathrm{R}^{2}=0.15, \mathrm{~F}(3,340)=19.70, p<0.001 ; \mathrm{QFI}: \mathrm{R}^{2}=0.15$, $\mathrm{F}(3,339)=, p<0.001)$. Thus, each of the three alcohol variables (AL, DHD, and QFI), as well as ASPD symptoms, were associated with impaired Digit Symbol performance, and women scored higher than men.

For the WAIS Block Design subtest, the multiple regression analyses indicated that AL, Gender, and their interaction significantly predicted the scores $\left(\mathrm{R}^{2}=0.06, \mathrm{~F}(3,341)=6.84\right.$, $p<0.001)$. Two three-way interactions with drinking variables were significant: $\mathrm{DHD} \times \mathrm{ASPD} \times \operatorname{Gender}\left(\mathrm{R}^{2}=0.06\right.$, $\mathrm{F}(7,335)=2.89, p<0.01)$ and $\mathrm{QFI} \times \mathrm{ASPD} \times$ Gender $\left(\mathrm{R}^{2}=0.06, \mathrm{~F}(7,332)=2.90, p<0.01\right)$. Men without a drinking history performed better than the other three groups; that is, they performed better than the nonalcoholic women, and better than the alcoholics of both genders. Increased duration and amount of drinking were associated with lower scores for women with ASPD symptoms; men did not show this connection.

For the WAIS Picture Arrangement subtest, all three alcohol-related predictors significantly interacted with $\operatorname{ASPD}\left(\mathrm{AL}: \mathrm{R}^{2}=0.03, \mathrm{~F}(3,341)=3.44, p<0.05\right)$;
DHD: $\left.\mathrm{R}^{2}=0.02, \mathrm{~F}(3,340)=2.94, p<0.05\right)$; and QFI: $\left.\mathrm{R}^{2}=0.04, \mathrm{~F}(3,336)=4.49, p<0.01\right)$. Alcoholics with comorbid ASPD symptoms performed significantly worse than alcoholics without ASPD; nonalcoholics did not show this relationship. Similarly, for all individuals with ASPD symptoms, DHD and QFI each predicted lower scores, and individuals without ASPD symptoms did not show this association.

\section{Measures of affect}

\section{Hamilton Depression Scale}

The regression equation with the AL x ASPD interaction for Hamilton Depression scores was significant $\left(\mathrm{R}^{2}=0.15\right.$, $\mathrm{F}(3,341)=21.02, p<0.001)$. Further, the interaction of DHD $\times$ ASPD, along with the predictor of Gender, also significantly predicted Hamilton Depression scores $\left(\mathrm{R}^{2}=0.16, \mathrm{~F}(4,339)=17.90, p<0.001\right)$. Comorbidity of ASPD symptoms with alcoholism, especially in alcoholics with a long DHD, was associated with the highest depression scores, and more so for women than for men.

\section{Profile of Moods (POMS) affect scores}

On the Anger scale of the POMS, the main effect of AL and the ASPD $\times$ Gender interaction were significant predictors $\left(\mathrm{R}^{2}=0.06, \mathrm{~F}(4,257)=4.31, p<0.01\right)$. Also, DHD alone was a significant predictor $\left(\mathrm{R}^{2}=0.02, \mathrm{~F}(1,259)=4.57, p<0.05\right)$. These findings indicated that high Anger scores on the POMS were associated with increased DHD. In addition, men with ASPD symptoms had higher Anger scores than men without ASPD symptoms, but women did not show this difference. On the POMS Depression scale, the main effect of AL, and the interaction of ASPD $\times$ Gender were significant $\left(\mathrm{R}^{2}=0.11\right.$, $\mathrm{F}(4,257)=8.23, p<0.001)$; the men with ASPD symptoms had higher Depression scores than the women. In addition, the main effect of Gender, as well as the DHD $\times$ ASPD interaction, significantly predicted POMS Depression scores $\left(\mathrm{R}^{2}=0.12, \mathrm{~F}(4,256)=8.81, p<0.001\right)$. In other words, longer drinking histories were associated with increased depression, but even more so in individuals with ASPD symptoms. With respect to the POMS Tension measure, AL, DHD, and ASPD were significant main effects $\left(\mathrm{AL}: \mathrm{R}^{2}=0.07, \mathrm{~F}(2,259)=9.36\right.$, $p<0.001$; DHD: $\left.\mathrm{R}^{2}=0.07, \mathrm{~F}(2,258)=9.79, p<0.001\right)$. These results showed that longer DHDs as well as ASPD symptoms were associated with increased Tension scores.

\section{Discussion}

In the present study, we employed a multivariate approach to evaluate the connection between alcoholism and ASPD 
symptoms on measures of prefrontal brain functioning. Our findings confirmed results of other studies showing that alcoholism and ASPD, separately, are associated with deficits on tests of frontal brain integrity. ${ }^{13,55}$ We found that AL, DHD, QFI, and ASPD were significant predictors on several measures of frontal dysfunction. Moreover, our findings further extended those results by showing that alcoholism and ASPD symptoms, together as comorbid conditions, were associated with synergistic frontal system deficits: They exceeded the sum of frontal deficits attributable to alcoholism plus those attributable to ASPD symptoms. This synergism was observed for tests sensitive both to dorsolateral prefrontal functions (Trails tests, WCST conceptual responses, and WAIS Block Design) and to orbitofronal functions (WAIS Picture Arrangement, and Depression).

With respect to gender differences, some of our results supported findings from the literature that neuropsychological deficits in association with alcohol variables were more pronounced for women than for men, ${ }^{43,44,76}$ and conversely, that the deficits with regard to ASPD were more pronounced for men than for women. ${ }^{36,38,40}$ However, our gender differences were not consistent across the tasks. Moreover, the men and women in the present study differed with respect to impairments associated with the co-occurrence of alcoholism and ASPD. In the following sections, the findings from each of the measures are discussed in turn, followed by a summary consideration of gender differences.

\section{Trails $A$ and Trails $B$}

The interaction of DHD with ASPD and Gender significantly predicted performance on Trails A in the present study. Stevens and colleagues ${ }^{42}$ reported that an interaction of an antisocial profile and family history for alcohol dependence significantly predicted Trails A completion time in men; women were not included in that study. For Trails B, we found significant interactions for each of the alcohol variables with ASPD and Gender. The fact that AL, DHD, and QFI predicted poor performance on Trails B is in concert with observations of Moriyama and colleagues ${ }^{77}$ and Davies and colleagues, ${ }^{78}$ who also reported deficits in alcoholic patients. Our results further suggested that the Trails deficits, which were associated with a combination of ASPD and drinking, were more pronounced for women than for men.

\section{Wisconsin Card Sorting Task (WCST)}

There were significant main effects of AL and ASPD on WCST perseverative response scores. Because the WCST requires set-switching, these findings support the proposed link of orbitofrontal system dysfunction to impulsive and disinhibited behavior. ${ }^{36,79,80}$ Moreover, the findings are in concert with those of Deckel, ${ }^{81}$ who reported an association of alcoholism and WCST deficits, and those of Oscar-Berman and colleagues ${ }^{18}$ who reported an increased number of perseverative responses among alcoholic Korsakoff patients. In addition, in the present study, the AL $\times$ ASPD interaction for conceptual level responding suggested greater dorsolateral prefrontal impairments associated with the combined conditions than deficits attributable to either condition alone.

\section{Controlled Oral Word Association Test (COWAT or FAS)}

For several of the FAS measures, ie, total number of words generated, age and education corrected percentiles, and perseverations, alcohol-related measures formed significant models with Gender. That is, increased drinking was associated with fewer words produced, and women generated more words than men. There also were significant main effects of AL, DHD, QFI, ASPD, and Gender in the models that predicted FAS percentiles. For FAS total number of perseverations, the significant three-way interaction of $\mathrm{DHD} \times \mathrm{ASPD} \times$ Gender suggested that men without ASPD symptoms exhibited a stronger connection between drinking and perseveration than men with ASPD symptoms. This interpretation should be heeded with caution because the overall low frequency of perseverative responses allowed a few individuals to have greater influence on the statistical outcome. $^{42,82}$

\section{Ruff Figural Fluency Test (RFFT)}

The interactions of AL with Gender, and DHD with Gender, significantly predicted performance on the number of unique designs on the RFFT. Whereas alcoholic men made fewer unique designs than nonalcoholic men, and longer DHDs in men predicted fewer unique designs, these relationships were not seen in women. Individuals with ASPD symptoms were also impaired on the task. The RFFT is often used as a measure of executive skills, as it requires planning and organizing to produce as many unique designs as possible during the time limit. Since these skills are considered to be controlled by the dorsolateral prefrontal system, our findings support the view that alcohol consumption by men, as well as ASPD symptoms in both genders, contribute to dorsolateral prefrontal dysfunction.

Of note, other studies have examined RFFT performance among alcoholics, and our findings support those of OscarBerman and colleagues ${ }^{18}$ who found that alcoholic Korsakoff 
patients had a significantly reduced number of unique designs on this test. By contrast, Blume and colleagues ${ }^{82}$ examined the number of unique designs and perseverative errors on the RFFT among nonabstinent alcoholics, and the investigators did not find the RFFT to significantly predict self-report scores on self-awareness of problem drinking or readiness to change drinking behavior.

\section{WAIS subtests (age scaled scores)}

A limited number of studies have used WAIS Performance subtests to assess frontal system dysfunction and social cognitive ability in patients with neurobehavioral disorders. On the Digit Symbol subtest of the WAIS, the main effects of AL, DHD, QFI, ASPD, and Gender significantly predicted performance. These findings support those of others ${ }^{14,78,83}$ who found that alcoholics, and in particular alcoholics who drank heavily, ${ }^{18}$ performed poorly on this subtest. However, we are among only a few who have reported poor Digit Symbol performance in association with ASPD symptoms. ${ }^{84}$ We also confirmed findings that, overall, women performed significantly better than men on Digit Symbol. ${ }^{85-89}$

On the Block Design subtest of the WAIS, the interaction of Gender and AL significantly predicted performance. Alcoholic men, and both alcoholic and nonalcoholic women performed significantly worse than men without a drinking history. Thus, we confirmed results of previous studies showing that alcoholic men are impaired on Block Design. ${ }^{90}$ However, in the present study, we found that alcoholic women were equivalent to nonalcoholic women. This finding differs from that of other investigators, who reported that alcoholic women are impaired on Block Design. ${ }^{91}$ We attribute the lack of impairment in our sample of alcoholic women to their long sobriety durations (mean of 6.6 years) and limited number of additional psychiatric diagnoses compared to other samples. ${ }^{91}$ The women with ASPD symptoms - but not the men - had lower scores in association with longer durations and higher amounts of drinking.

On the Picture Arrangement subtest of the WAIS, the interaction of ASPD with each of the three alcohol variables (AL, DHD, and QFI), significantly predicted performance. Picture Arrangement performance involves widespread frontal brain regions, because successful performance requires the weighing of multiple options and possible outcomes of a social situation presented to the participant, while at the same time, using working memory to organize the pictures cohesively. The Picture Arrangement subtest has been used previously to assess frontal system function. ${ }^{92-94}$ In addition, orbitofrontal deficits are presumed, because several studies have found this subtest to measure social cognitive functioning in patients with psychiatric diagnoses $^{95,96}$ (although there is no general consensus for this assumption). ${ }^{96}$ We also found that alcoholics with ASPD symptoms performed worse on Picture Arrangement as DHD increased. Our findings are robust, since the AL $\times$ ASPD, $\mathrm{DHD} \times \mathrm{ASPD}$, and QFI $\times$ ASPD interactions significantly predicted Picture Arrangement scores, thereby supporting the view that individuals with ASPD symptoms who drink excessively have greater impairments on frontal tasks than those who drink less.

\section{Measures of affect}

Several studies have reported relationships between alcoholism, ASPD, negative affectivity, and emotional dysregulation. ${ }^{8,34,97-99}$ The findings from this study support those previous findings, indicating that, indeed, there were significant interactions between ASPD and drinking variables (AL and DHD) on the Hamilton Depression Scale: Alcoholics with ASPD symptoms had higher Depression scores than nonalcoholics, and Depression scores were higher in individuals with ASPD symptoms as their drinking durations increased. While taking into consideration this interaction, Depression scores were higher in women than in men. Once more, these findings support an association between ASPD symptoms and frontal system dysfunction beyond that attributable to alcoholism alone.

On all three measures of the POMS, ie, Anger, Depression, and Tension, the alcoholics scored higher than the nonalcoholics, and the participants with ASPD symptoms scored higher than those without. Higher Anger and Depression scores also were associated with increased duration of drinking, and individuals with ASPD symptoms who drank for the longest time had the highest Depression scores. Finally, in concert with other research, ${ }^{100}$ we found that men with ASPD symptoms had higher Anger and Depression scores on the POMS than did women.

\section{Gender}

With respect to gender, our results confirmed the findings of others, showing that women performed better than men on the FAS test ${ }^{92,101-104}$ and the WAIS Digit Symbol subtest, ${ }^{85-89}$ whereas men performed better than women overall on the Block Design subtest. ${ }^{85,88}$ A more complex pattern of gender interactions was observed with respect to alcohol-related variables and ASPD symptoms for all of our measures except for the WCST and the WAIS Picture Arrangement Subtest, in which we observed no gender differences. Overall, our results 
did not support those of other investigators who reported that women were generally more vulnerable to the effects of alcoholism than men..$^{44,76,105}$ That is, for three measures, FAS perseverations, RFFT, and Block Design, men were more impaired in relation to alcohol variables than women, ${ }^{41,106,107}$ while the opposite was found for the Trails tests.

The results of the present study confirmed and extended previous findings that alcoholic as well as nonalcoholic men have more ASPD symptoms than women., ${ }^{3,45}$ Additionally, men with ASPD symptoms had higher negative affect scores on the POMS in comparison to women. ${ }^{100}$ Furthermore, for FAS perseverations and Block Design, the ASPD-related differences were larger for alcoholic men than women. For the Trails tests, the relationship with ASPD symptoms and alcohol variables was more pronounced in women.

\section{Limitations}

Psychometric properties are not available for our medical and alcohol screening interviews, and although norms have been established with alcoholic participants for the WAIS, WMS, WCST, and Trails, we know of no norms relevant to ASPD populations for the measures we used in our study. Additionally, and as noted earlier, we characterized our ASPD group as having "ASPD symptoms," because measures of the presence or absence of conduct disorder were not available from many participants. Therefore, our sample of individuals with ASPD symptoms may not be representative of patients with a formal psychiatric diagnosis of ASPD. In any case, our results demonstrated a clear synergism between alcoholism and ASPD symptoms with respect to the presence of frontal deficits.

Another limitation of this study is that we did not examine ASPD severity (as measured by number of symptoms) among alcoholics and nonalcoholics. Stevens and colleagues ${ }^{42}$ reported that a greater number of ASPD symptoms were associated with slightly decreased scores in verbal abstraction, a measure of executive cognitive function. Further investigations of ASPD symptom severity and the effects of alcoholism on executive function are needed.

Additionally, exclusion criteria for participation in our study included significant psychiatric disorder such as bipolar disorder, mania, hypomania, and schizophrenia-spectrum disorders. However, other personality pathology, including panic disorder, posttraumatic stress disorder, and disorders characterized by high levels of impulsivity (eg, borderline), were not exclusion criteria and might confound associations of antisociality and alcohol use disorders with the neuropsychological deficits examined in this study.

\section{Conclusions}

This study examined the influence of alcoholism and ASPD symptoms on neuropsychological test performance sensitive to frontal brain dysfunction in men and women. We found that men and women were affected differently by the comorbidity of alcoholism and ASPD symptoms, depending upon the task. We also observed impairments, unrelated to gender differences, in performance between alcoholics with and without ASPD symptoms on measures of dorsolateral and orbitofrontal frontal system integrity. As hypothesized, there were significant interactions of alcohol-related measures with ASPD on several neuropsychological tests. In addition, we found that the drinking variables and ASPD were strong predictors of negative affect. That is, ASPD (or an interaction with ASPD) predicted significantly over and above alcoholism and duration of heavy drinking. In other words, we obtained evidence that the combination of alcoholism and ASPD symptoms led to greater deficits than the sum of each.

It has been reported ${ }^{55}$ that among ASPD subjects, increased alcohol consumption predicted poor neuropsychological performance. Thus, clinicians treating patients with alcoholism may provide more effective treatment when considering that personality disorders such as ASPD contribute to frontal dysfunction resulting in impulsivity, disinhibition, compulsivity, negative affectivity, and emotional dysregulation. These factors are related to drinking behaviors, which in turn, can complicate treatment and lead to poor treatment outcomes. Therefore, ASPD symptoms must be carefully examined in order to facilitate accurate and timely evaluations of alcoholic patients, as well as to anticipate and counter potential difficulties inherent in treating dual diagnosis patients.

\section{Acknowledgments}

This research was supported by funds from the US Department of Health and Human Services, NIAAA (R01-AA07112 and K05-AA00219) to Boston University, and by funds from the Medical Research Service of the US Department of Veterans Affairs. Claribel Yu and Kimberly Wall helped with data collection.

\section{References}

1. Compton WM, Conway KP, Stinson FS, Colliver JD, Grant BF Prevalence, correlates, and comorbidity of DSM-IV antisocial personality syndromes and alcohol and specific drug use disorders in the United States: results from the national epidemiologic survey on alcohol and related conditions. J Clin Psychiatry. 2005;66(6):677-685.

2. Di Sclafani V, Finn P, Fein G. Psychiatric comorbidity in long-term abstinent alcoholic individuals. Alcohol Clin Exp Res. 2007;31(5): $795-803$. 
3. Goldstein RB, Dawson DA, Saha TD, Ruan WJ, Compton WM, Grant BF. Antisocial behavioral syndromes and DSM-IV alcohol use disorders: results from the National Epidemiologic Survey on Alcohol and Related Conditions. Alcohol Clin Exp Res. 2007;31(5):814-828.

4. Tragesser SL, Trull TJ, Sher KJ, Park A. Drinking motives as mediators in the relation between personality disorder symptoms and alcohol use disorder. J Pers Disord. 2008;22(5):525-537.

5. Finn PR, Mazas CA, Justus AN, Steinmetz J. Early-onset alcoholism with conduct disorder: go/no go learning deficits, working memory capacity, and personality. Alcohol Clin Exp Res. 2002;26(2):186-206.

6. Mazas CA, Finn PR, Steinmetz JE. Decision-making biases, antisocial personality, and early-onset alcoholism. Alcohol Clin Exp Res. 2000; 24(7):1036-1040.

7. Sher KJ, Slutske WS. Disorders of impulse control. In: Stricker G, Widiger TA, editors. Handbook of Psychology: Clinical psychology. Volume 8. Hoboken, NJ: John Wiley and Sons; 2003. p. 195-228.

8. Trull TJ, Waudby CJ, Sher KJ. Alcohol, tobacco, and drug use disorders and personality disorder symptoms. Exp Clin Psychopharmacol. 2004;12(1):65-75.

9. Davidson KM, Tyrer P, Tata P, et al. Cognitive behaviour therapy for violent men with antisocial personality disorder in the community: an exploratory randomized controlled trial. Psychol Med. 2008;30:1-9.

10. Mayer AR, Kosson DS, Bedrick EJ. Neuropsychological implications of selective attentional functioning in psychopathic offenders. Neuropsychology. 2006;20(5):614-624.

11. Blair KS, Newman C, Mitchell DG, et al. Differentiating among prefrontal substrates in psychopathy: neuropsychological test findings. Neuropsychology. 2006;20(2):153-165.

12. Mitchell DG, Fine $\mathrm{C}$, Richell RA, et al. Instrumental learning and relearning in individuals with psychopathy and in patients with lesions involving the amygdala or orbitofrontal cortex. Neuropsychology. 2006;20(3):280-289.

13. Oscar-Berman M, Marinkovic K. Alcohol: effects on neurobehavioral functions and the brain. Neuropsychol Rev. 2007;17(3):239-257.

14. Ratti MT, Bo P, Giardini A, Soragna D. Chronic alcoholism and the frontal lobe: which executive functions are imparied? Acta Neurol Scand. 2002;105(4):276-281.

15. Dolan M, Park I. The neuropsychology of antisocial personality disorder. Psychol Med. 2002;32(3):417-427.

16. Morgan AB, Lilienfeld SO. A meta-analytic review of the relation between antisocial behavior and neuropsychological measures of executive function. Clin Psychol Rev. 2000;20(1):113-136.

17. Oscar-Berman M, Hutner N. Frontal lobe changes after chronic alcohol ingestion. In: Hunt WA, Nixon SJ, editors. Alcohol-Induced Brain Damage (NIAAA Research Monograph No 22). Rockville, IN: US Department of Health and Human Services, NIH Publication No. 93-3549, 1993:121-156.

18. Oscar-Berman M, Kirkley SM, Gansler DA, Couture A. Comparisons of Korsakoff and non-Korsakoff alcoholics on neuropsychological tests of prefrontal brain functioning. Alcohol Clin Exp Res. 2004; 28(4):667-675.

19. Oscar-Berman M, Bowirrat A. Genetic influences in emotional dysfunction and alcoholism-related brain damage. Neuropsychiatr Dis Treat. 2005;1(3):211-229.

20. Hesselbrock MN. Gender comparison of antisocial personality disorder and depression in alcoholism. $J$ Subst Abuse. 1991;3(2):205-219.

21. Pihl RO, Peterson JB. A biobehavioural model for the inherited predisposition to alcoholism. Alcohol Alcohol. 1991;1(Suppl):151-156.

22. Holdcraft LC, Iacono WG, McGue MK. Antisocial personality disorder and depression in relation to alcoholism: a community-based sample. J Stud Alcohol. 1998;59(2):222-226.

23. Cloninger CR. Neurogenetic adaptive mechanisms in alcoholism. Science. 1987;236(4800):410-416.

24. Laakso MP, Gunning-Dixon F, Vaurio O, Repo-Tiihonen E, Soininen H, Tiihonen J. Prefrontal volumes in habitually violent subjects with antisocial personality disorder and type 2 alcoholism. Psychiatry Res. 2002;114(2):95-102.
25. Sperling W, Frank H, Martus $\mathrm{P}$, et al. The concept of abnormal hemispheric organization in addiction research. Alcohol Alcohol. 2000;35(4):394-399.

26. Virkkunen M, Rawlings R, Tokola R, et al. CSF biochemistries, glucose metabolism, and diurnal activity rhythms in alcoholic, violent offenders, fire setters, and healthy volunteers. Arch Gen Psychiatry. 1994; 51(1):20-27.

27. Raine A, Buchsbaum M, LaCasse L. Brain abnormalities in murderers indicated by positron emission tomography. Biol Psychiatry. 1997; 42(6):495-508

28. Kuruoglu AC, Arikan Z, Vural G, Karatas M, Arac M, Isik E. Single photon emission computerised tomography in chronic alcoholism. Antisocial personality disorder may be associated with decreased frontal perfusion. Br J Psychiatry. 1996;169(3):348-354.

29. Fuster JM. The prefrontal cortex. 4th ed. New York, NY: Academic Press; 2008.

30. Oscar-Berman M, Bardenhagen F. Nonhuman animal models of memory dysfunction in neurodegenerative disease. In: Troster A, editor. Memory in neurodegenerative disease. New York, NY: Cambridge University Press; 1998. p. 3-20.

31. Miller BL, Cummings JL. The human frontal lobes: functions and disorders. 2nd ed. New York, NY: The Guilford Press; 2007.

32. Royall DR, Lauterbach EC, Cummings JL, et al. Executive control function: a review of its promise and challenges for clinical research. A report from the Committee on Research of the American Neuropsychiatric Association. Journal of Neuropsychiatry and Clinical Neuroscience. 2002;14(4):377-405.

33. Rolls ET. Convergence of sensory systems in the orbitofrontal cortex in primates and brain design for emotion. Anat Rec A Discov Mol Cell Evol Biol. 2004;281(1):1212-1225.

34. Clark US, Oscar-Berman M, Shagrin B, Pencina M. Alcoholism and judgments of affective stimuli. Neuropsychology. 2007;21(3): 346-362.

35. Blake PY, Pincus JH, Buckner C. neurologic abnormalities in murderers. Neurology. 1995;45(9):1641-1647.

36. Damasio AR, Anderson SW. The frontal lobes. In: Heilman KM, Valenstein E, editors. Clinical neuropsychology. 4th ed. New York, NY: Oxford University Press; 2003. p. 404-436.

37. Damasio AR, Tranel D, Damasio H. Individuals with socio-pathic behavior caused by frontal damage fail to respond autonomically to social stimuli. Behav Brain Res. 1990;41:81-94.

38. Grafman J, Schwab K, Warden D, Pridgen A, Brown HR, Salazar AM. Frontal lobe injuries, violence, and aggression: a report of the Vietnam Head Injury Study. Neurology. 1996;46(5):1231-1238.

39. Miller BJ, Cummings JL. The human frontal lobes: functions and disorders. 1st ed. New York, NY: The Guilford Press; 1999.

40. Ogden JA. Fractured minds: a case-study approach to clinical neuropsychology. 2nd ed. New York, NY: Oxford University Press; 2005.

41. Cale EM, Lilienfeld SO. Sex differences in psychopathy and antisocial personality disorder. A review and integration. Clin Psychol Rev. 2002; 22(8):1179-1207.

42. Stevens MC, Kaplan RF, Hesselbrock VM. Executive-cognitive functioning in the development of antisocial personality disorder. Addict Behav. 2003;28(2):285-300.

43. Tapert SF, Brown GG, Kindermann SS, Cheung EH, Frank LR, Brown SA. fMRI measurement of brain dysfunction in alcoholdependent young women. Alcohol Clin Exp Res. 2001;25(2):236-245.

44. Mann K, Ackermann K, Croissant B, Mundle G, Nakovics H, Diehl A. Neuroimaging of gender differences in alcohol dependence: are women more vulnerable? Alcohol Clin Exp Res. 2005;29(5):896-901.

45. McGue M, Slutske W, Taylor J, Iacono WG. Personality and substance use disorders: I. Effects of gender and alcoholism subtype. Alcohol Clin Exp Res. 1997;21(3):513-520.

46. Raine A, Lencz T, Bihrle S, LaCasse L, Colletti P. Reduced prefrontal gray matter volume and reduced autonomic activity in antisocial personality disorder. Arch Gen Psychiatry. 2000;57(2):119-127; discussion $128-129$. 
47. Robins LN, Helzer J, Cottler LB, Goldring E. NIMH Diagnostic Interview Schedule: Version III Revised (DIS-III-R). St. Louis, MO: Washington University; 1989.

48. Robins LN, Cottler LB, Bucholz KK, Compton WM, North CS, Rourke KM. NIMH Diagnostic Interview Schedule for the DSM-IV (DIS-IV). St. Louis, MO: Washington University; 2000.

49. Americal Psychiatric Association. Diagnostic and Statistical Manual of Mental Disorders, Third Edition Revised (DSM-III-R). Washington, DC: American Psychiatric Association; 1987.

50. Americal Psychiatric Association. Diagnostic and Statistical Manual of Mental Disorders, Fourth Edition (DSM-IV). Washington, DC: American Psychiatric Association; 1994.

51. Cahalan V, Cisin I, Crossley HM. American drinking practices: A national study of drinking behavior and attitudes. Report 6. New Brunswick, NJ: Rutgers Center for Alcohol Studies; 1969.

52. Buros. The Buros Institute's Mental Measurements Yearbook Online Database. Boston, MA: EBSCO Publishers; 2001-2009.

53. Dascalu M, Compton WM, Horton JC, Cottler LB. Validity of DIS-IV in diagnosing depression and other psychiatric disorders among substance users. Drug Alcohol Depend. 2001; 63(37):S37.

54. Horton JC, Compton WM, Cottler LB. Assessing psychiatric disorders among drug users: reliability of the revised DIS-IV. In: Harris L, editor NIDA research monograph - Problems of drug dependence 1998. Publication No 99-4395. Washington, DC: NIH; 1999. p. 205.

55. Waldstein SR, Malloy PF, Stout R, Longabaugh R. Predictors of neuropsychological impairment in alcoholics: antisocial versus nonantisocial subtypes. Addict Behav. 1996;21(1):21-27.

56. Wechsler D. WAIS-R Manual: Wechsler Adult Intelligence ScaleRevised. New York, NY: Psychological Corporation; 1981.

57. Wechsler D. WAIS III manual: Wechsler Adult Intelligence Scale-Third Edition. San Antonio, TX: The Psychological Corporation, Harcourt Brace and Company; 1997.

58. Wechsler D. Wechsler Memory Scale-Revised. New York, NY: The Psychological Corporation; 1987.

59. Wechsler D. WMS-III Manual: Wechsler Memory Scale-Third Edition. San Antonio, TX: The Psychological Corporation, Harcourt Brace and Company; 1997.

60. Lezak MD. Neuropsychological assessment. 3rd ed. New York, NY: Oxford University Press; 1995.

61. Spreen O, Strauss E. A compendium of neuropsychological tests. New York, NY: Oxford University Press; 1998.

62. US Army. Army Individual Test Battery. Manual of directions and scoring. Washington, DC: War Department, Adjutant General's Office; 1944.

63. Grant DA, Berg EA. A behavioral analysis if degree of reinforcement and ease of shifting to new responses in a Weigl-type card-sorting problem. J Exp Psychology. 1948;38:404-411.

64. Benton AL, Hamsher K, Silvan AB. Multilingual aphasia examination. 3rd ed. Iowa City, IA: AJA Associates; 1994.

65. Ruff R. Ruff Figural Fluency Test. San Diego, CA: Neuropsychological Resources, 1988.

66. Tombaugh TN, Kozak J, Rees L. Normative data stratified by age and education for two measures of verbal fluency: FAS and animal naming. Arch Clin Neuropsychol. 1999;14(2):167-177.

67. Chandler MJ. The Picture Arrangement Subtest of the WAIS as an index of social egocentrism: A comparative study of normal and emotionally disturbed children. J Abnorm Child Psychol. 1973;1(4):340-349.

68. Hamilton MA. A rating scale for depression. J Neurol Neurosurg Psychiatry. 1960(23):56-62.

69. McNair DM, Lorr M, Droppleman LF. Profile of Mood States (POMS) manual. San Diego, CA: Educational and Industrial Testing Service; 1971.

70. McMahon RC, Davidson RS. Patterns of stability and change in mood states of alcoholics in inpatient treatment. Int J Addict. 1986; 21(8):923-927.

71. Robbins BJ, Brotherton PL. Mood change with alcohol intoxication. Br J Soc Clin Psychol. 1980;19(2):149-155.
72. McMahon RC, Davidson RS, Flynn PM. Psychological correlates and treatment outcomes for high and low social functioning alcoholics. Int J Addict. 1986;21(7):819-835.

73. Statistical Package for the Social Sciences I. SPSS Version 16. Chicago, IL: SPSS Inc; 2007.

74. Giambra LM, Arenberg D, Kawas C, Zonderman AB, Costa PT, Jr. Adult life span changes in immediate visual memory and verbal intelligence. Psychol Aging. 1995;10(1):123-139.

75. Schottenbauer MA, Momenan R, Kerick M, Hommer DW. Relationships among aging, IQ, and intracranial volume in alcoholics and control subjects. Neuropsychology. 2007;21(3):337-345.

76. Nixon SJ. Cognitive deficits in alcoholic women. Alcohol Health Res World. 994;18(3):228-232.

77. Moriyama Y, Mimura M, Kato M, et al. Executive dysfunction and clinical outcome in chronic alcoholics. Alcohol Clin Exp Res. 2002; 26(8):1239-1244.

78. Davies SJ, Pandit SA, Feeney A, et al. Is there cognitive impairment in clinically 'healthy' abstinent alcohol dependence? Alcohol Alcohol. 2005;40(6):498-503.

79. Barratt ES. Impulsiveness defined within a systems model of personality. In: Spielberger EP, Butcher JN, editors. Advances in personality assessment. Hillsdale, NJ: Lawrence Erlbaum; 1985. p. 113-132.

80. Torregrossa MM, Quinn JJ, Taylor JR. Impulsivity, compulsivity, and habit: the role of orbitofrontal cortex revisited. Biol Psychiatry. 2008; 63(3):253-255.

81. Deckel AW. Tests of executive functioning predict scores on the MacAndrew Alcoholism Scale. Progress in Neuropsychopharmacology and Biological Psychiatry. 1999;23(2):209-223.

82. Blume AW, Schmaling KB, Marlatt GA. Memory, executive cognitive function, and readiness to change drinking behavior. Addict Behav. 2005;30(2):301-314.

83. Rourke SB, Loberg T. The neurobehavioral correlates of alcoholism. In: Grant I, Nixon SJ, editors. Neuropsychological assessment of neuropsychiatric disorders. 2nd ed. New York, NY: Oxford University Press; 1996. p. 423-485.

84. Barratt ES, Stanford MS, Kent TA, Felthous A. Neuropsychological and cognitive psychophysiological substrates of impulsive aggression. Biol Psychiatry. 1997;41(10):1045-1061.

85. Fein G, Torres J, Price LJ, Di Sclafani V. Cognitive performance in long-term abstinent alcoholic individuals. Alcohol Clin Exp Res. 2006;30(9):1538-1544.

86. Herlitz A, Yonker JE. Sex differences in episodic memory: the influence of intelligence. J Clin Exp Neuropsychol. 2002;24(1):107-114.

87. Hesselbrock MN, Weidenman MA, Reed HB. Effect of age, sex, drinking history and antisocial personality on neuropsychology of alcoholics. J Stud Alcohol. 1985;46(4):313-320.

88. Portin R, Saarijarvi S, Joukamaa M, Salokangas RK. Education, gender and cognitive performance in a 62-year-old normal population: results from the Turva Project. Psychol Med. 1995;25(6): 1295-1298.

89. Snow WG, Weinstock J. Sex differences among non-brain-damaged adults on the Wechsler Adult Intelligence Scales: a review of the literature. J Clin Exp Neuropsychol. 1990;12(6):873-386.

90. Ellis RJ, Oscar-Berman M. Alcoholism, aging, and functional cerebral asymmetries. Psychol Bull. 1989;106(1):128-147.

91. Sullivan EV, Fama R, Rosenbloom MJ, Pfefferbaum A. A profile of neuropsychological deficits in alcoholic women. Neuropsychology. 2002; 16(1):74-83.

92. Boone KB, Miller BL, Lee A, Berman N, Sherman D, Stuss DT. Neuropsychological patterns in right versus left frontotemporal dementia. J Int Neuropsychol Soc. 1999;5(7):616-622.

93. McFie J, Thompson JA. Picture arrangement: a measure of frontal lobe function? Br J Psychiatry. 1972;121(564):547-552.

94. Melrose RJ, Tinaz S, Castelo JM, Courtney MG, Stern CE. Compromised fronto-striatal functioning in HIV: an fMRI investigation of semantic event sequencing. Behav Brain Res. 2008 Apr 9;188(2): $337-347$. 
95. Allen DN, Strauss GP, Donohue B, van Kammen DP. Factor analytic support for social cognition as a separable cognitive domain in schizophrenia. Schizophr Res. 2007;93(1-3):325-333.

96. Campbell JM, McCord DM. Measuring social competence with the Wechsler Picture Arrangement and Comprehension subtests. Assessment. 1999; 6(3):215-224.

97. Ducci F, Enoch MA, Funt S, Virkkunen M, Albaugh B, Goldman D. Increased anxiety and other similarities in temperament of alcoholics with and without antisocial personality disorder across three diverse populations. Alcohol. 2007; 41(1):3-12.

98. Hasin DS, Stinson FS, Ogburn E, Grant BF. Prevalence, correlates, disability, and comorbidity of DSM-IV alcohol abuse and dependence in the United States: results from the National Epidemiologic Survey on Alcohol and Related Conditions. Arch Gen Psychiatry. 2007;64(7): 830-842.

99. Tragesser SL, Sher KJ, Trull TJ, Park A. Personality disorder symptoms, drinking motives, and alcohol use and consequences: cross-sectional and prospective mediation. Exp Clin Psychopharmacol. 2007;15(3): 282-292.

100. Hoaken PN, Giancola PR, Pihl RO. Executive cognitive functions as mediators of alcohol-related aggression. Alcohol Alcohol. 1998; 33(1):47-54
101. Bolla KI, Lindgren KN, Bonaccorsy C, Bleecker ML. Predictors of verbal fluency (FAS) in the healthy elderly. J Clin Psychology. 1990; 46(5):623-628.

102. Boone KB, Lu P. Gender effects in neuropsychological assessment. In: Fletcher-Janzen E, Strickland TL, Reynolds CR, editors. Handbook of cross-cultural neuropsychology. New York, NY: Kluwer Academic/ Plenum Publishers, 2000. p. 73-86.

103. Ruff RM, Light RH, Parker SB, Levin HS. Benton Controlled Oral Word Association Test: reliability and updated norms. Arch Clin Neuropsychol. 1996;11(4):329-338.

104. Ryan JP, Atkinson TM, Dunham KT. Sports-related and gender differences on neuropsychological measures of frontal lobe functioning. Clin J Sport Med. 2004;14(1):18-24.

105. Hewett LJ, Nixon SJ, Glenn W, Parsons OA. Verbal fluency deficits in female alcoholics. J Clin Psychol. 1991;47(5):716-720.

106. Malloy P, Noel N, Rogers S, Longabaugh R, Beattie M. Risk factors for neuropsychological impairment in alcoholics: antisocial personality, age, years of drinking and gender. J Stud Alcohol. 1989; 50(5):422-426.

107. Yonker JE, Nilsson LG, Herlitz A, Anthenelli RM. Sex differences in spatial visualization and episodic memory as a function of alcohol consumption. Alcohol Alcohol. 2005;40(3):201-207.

\section{Publish your work in this journal}

Neuropsychiatric Disease and Treatment is an international, peerreviewed journal of clinical therapeutics and pharmacology focusing on concise rapid reporting of clinical or pre-clinical studies on a range of neuropsychiatric and neurological disorders. This journal is indexed on PubMed Central, the 'PsycINFO' database and CAS, and is the official journal of The International Neuropsychiatric Association (INA). The manuscript management system is completely online and includes a very quick and fair peer-review system, which is all easy to use. Visit http://www.dovepress.com/testimonials.php to read real quotes from published authors. 